\title{
Rare Presentation of Bilateral Sino-Nasal Inverted Papilloma
}

\author{
Dr.Vivek Kumar Pathak ${ }^{1,}$ Dr.(Prof.) Debajit Das ${ }^{2,}$ Dr.Uttal taranga Bhuyan ${ }^{3}$ \\ 1Corresponding auther,M.S.(ENT) Post-graduate student, department of otorhinolaryngology, Assam Medical \\ College , Dibrugarh, Assam. \\ 2M.S.(ENT), Professor\& HOD, department of otorhinolaryngology, Assam Medical College , Dibrugarh, \\ Assam \\ 3M.S.(ENT),Associate Professor, department of otorhinolaryngology ,Assam Medical College , Dibrugarh, \\ Assam \\ Paper presentated at $25^{\text {th }}$ Annual conference of NortheastnBranch of the association of otolaryngologists of \\ India,held at Guwahati,Assam,India on $2^{\text {nd }}$ November 2012
}

\begin{abstract}
Introduction: The inverted papilloma (IP ) is a rare and benign sinonasal tumour, bearing an incidence of 0.75-1.5 cases per 100 thousand inhabitants/ year( representing 0.5-4\%) of nasal tumours and 9199\% of cases are unilateral.IP is locally aggressive tumour having propensity for recurrence and association with malignancy, We Report a rare case of inverted papilloma in bilateral nasal cavity.

Case Report: A 54 Years old man presenting with history of bilateral nasal obstruction.

CT scan Nose and PNS revealed soft tissue density mass in bilateral nasal cavity,

Intra-operative bilateral ethmoid sinuses, Lt. maxillary, Lt. sphenoid sinus were found involved, Total removal was done endoscopically, On the basis of clinic-pathological findings, The tumour was diagnosed as inverted papilloma, On follow up patient was disease free .

Conclusion: The very rarity with which inverted papillomas affect the nasal cavities (bilateral) makes this report so important, especially considering post-operative follow up
\end{abstract}

\section{Introduction:}

The term papilloma means neoplasia with epithelial growth. The first report of this type of tumour in the nasal cavity was made by Ward et al. in 1854 .

The inverted papilloma ( IP ) is a rare and benign sinonasal tumour, bearing an incidence of 0.75-1.5 cases per 100 thousand inhabitants/ year( representing 0.5-4\% of nasal tumours and $91-99 \%$ of cases are unilateral .

IP originates from lateral wall of nasal cavity, and it secondarily affects the maxillary, ethmoid, sphenoid sinuses, IP are 4-5 times more frequent in males, between $5^{\text {th }}$ and $6^{\text {th }}$ decades of life ${ }^{[1,5]}$. Although benign, the IP is characterised by an aggressive growth, great invasion potential ${ }^{[1,6]}$, being multicentric $(12 \%)$ , high recurrence rate ${ }^{[1,5]}$ and malignancy $(2-53 \%)^{[1,5]}$, About $10 \%$ of the IP cases with cellular atypia are associated with squamous cell carcinoma ${ }^{[1,5]}$.

Signs and symptoms are nonspecific and may cause unilateral nasal obstruction, epitaxis, olfactory disorder and rhino sinusitis. Diagnosis is carried out by history taking, Otorhinolayrgological examination, Imaging (C.T. scan, M.R.I. ) . dysplasia .

Main differential diagnosis are antrochoanal polyp, Squamous papilloma of nasal cavity, fibrous

Treatment is surgical, surgical techniques and access must be broadly studied and individualised .

We report a rare case of inverted papilloma affecting bilateral nasal cavity, destroying nasal septum and anterior wall of sphenoid sinus .

\section{Case Report :}

A 54 Years old male complained of bilateral nasal obstruction for two years, associated with hyposmia and mucopurulent rhinorrhea. He didnot complains of Epistaxis, headache and visual impairment, Patient had undergoneRt. Caldwell-luc operation in 2008, bilateral polypectomy in 2010 for nasal polyposis .

On Examination :

On anterior rhinoscopy multiple polypoidal growths pinkish-white in colour ,insensitive to touchon probing were seen in bilateral nasal cavities .

On Diagnostic nasal endoscopymultiple firm polypoidal growths pinkish-white in colour, filling bilateral middle meatus were seen ,posterior part ofseptum andAnterior wall of Lt. sphenoid sinus were found eroded by mass . [Fig1,Fig2] 
CT scan Nose and PNS reaveled hyperdense irregular SOL noted in cranial part of nasal cavity above middle turbinate on left side and above inferior turbinate on right side involving bilateral ethmoidal sinuses, Rt. Maxillary sinus .[Fig3,Fig4]

Mass was endoscopically cleared from bilateral nasal cavity with sufficient clear margins all around [Fig5].Serialhistopathological examination revealed bilateral inverted papilloma without atypia [Fig6]. On postoperative follow up patient was disease free on endoscopic examination .

\section{Discussion:}

Inverted Papillomas are relatively uncommon bening epithelial tumours of the nasal cavity that generate considerable interest because they are locally aggressive have tendency to recur and are associated with malignancy. The incidence IP in apparently normal bilateral polyps varies between $0.00 \%$ and $0.92 \%{ }^{(7)}$

The incidence of IP in unremarkable recurrent cases o nasal polyp is rare .

IP is generally unilateral and bilateral involvement of sinonasal tract is very rare , reported in less than $1 \%-9 \%$ of patients ${ }^{(7)}$

Nasal polyps, 25 times more frequent than IPs (2), and must constitute a differential diagnosis, just like the antrochoanal polyp, squamouspolyp, nasal vestibule polyp, fibrous dysplasia, giant cellsgranuloma.

Human papilloma virus has been implicated in causing IP and its DNA has been found in both IP and normal mucosa surrounding it.

Treatment is wide excision of the tumour and approaches are lateral rhinotomy ,midfacial degloving with medial maxillectomy and endoscopic, Since 1980 endoscopic approach has gained popularity .Endoscopic medial maxillectomy has superseded Caldwell-Luc approach in vast majority of cases ${ }^{(7)}$

The morbidity with endoscopic approach is less with no facial incision, less facial swelling, short postoperative time, Recurrence are common and has been

\section{Conclusion:}

The very rarity with which inverted papillomas affecting thebilateral nasal cavities, destroying nasal septum and anterior wall of sphenoid sinus makes this report soimportant, especially considering occurrence of IP in previous benign inflammatory polyps and post-operative follow up because, despite being a benign tumour, the inverted papilloma is a very aggressive tumour with propensity towards malignency .

\section{References}

[1] Requel Salmone et al. , Bilateral inverted papilloma: case report and Literature review . Res Bras otorhinolarygol. 2008;74(2):293-6

[2] Vrabee DP, The inverted Schneiderian papilloma: 25 year study Laryngoscope 1994, 104:582-608.

[3] N.C. Lyngdoh,T.H. Ibohal,I.C. Marak,"A Study On The Clinical Profile And Management Of Inverted Papilloma”,Indian Journal Of Otorhinolaryngology, Head and Neck Surgery vol.58,no.15,March 2.

[4] Ringertz N. Pathology of malignant tumors arising in the nasal and paranasal cavities and maxilla. Acta Otolaryngol 1938;27:31-42.

[5] Oikawa K, Furuta Y, Oridate N, Nagahashi T, Homma A, Ryu T, Fukuda S. Preoperative staging of sinonasal inverted papilloma by magnetic resonance imaging. Laryngoscope 2003;133(11):1983-7.

[6] Alegre ACM, Ramos AHC, Voegels RL, Romano F. Papiloma e Papilloma invertido Em: Campos CA, Costa HOO. Tratado de Otorrinolaringologia. 1A ed. São Paulo: Roca; 2003. P126-32.

[7] Valerie Lund et al,"Endoscopic techniques in the management of Nose ,Paranasal sinus and skull base tumours “ on behalf of Rhinologic advisory board, Rhinology supplement 22

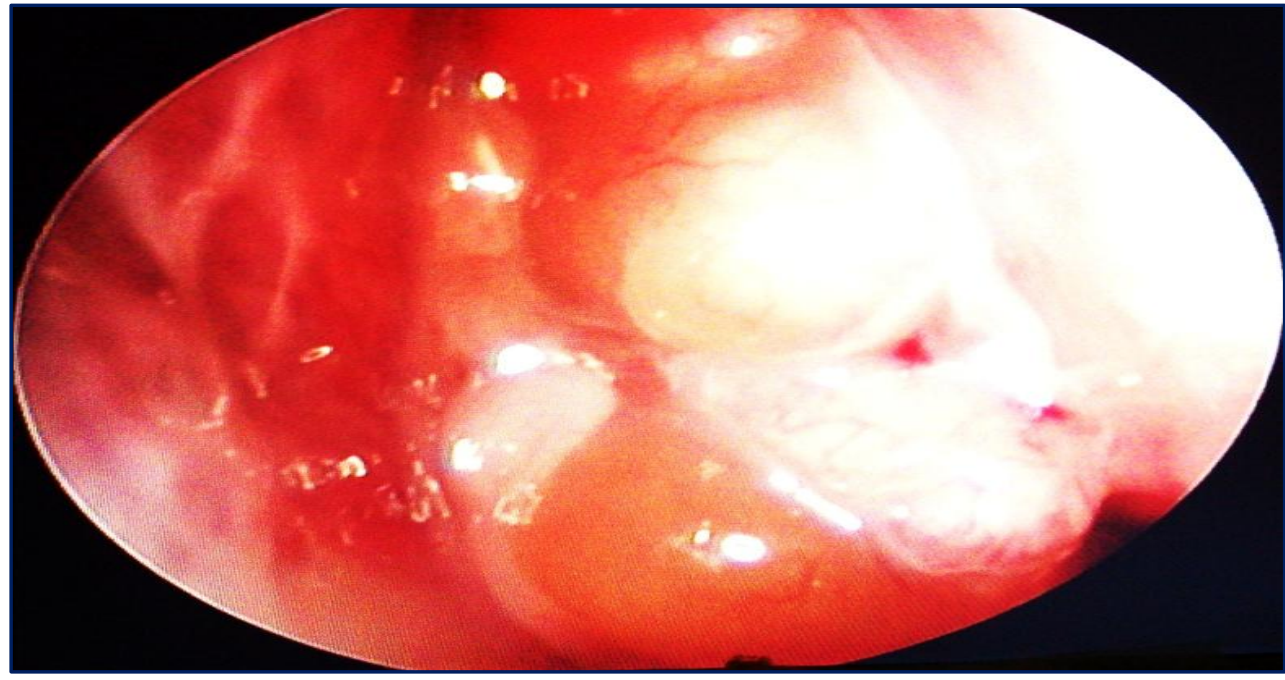

Fig1:Preopertive nasal endoscopy showing polypoidal mass in Lt. nasal cavity arising from middle meatus 


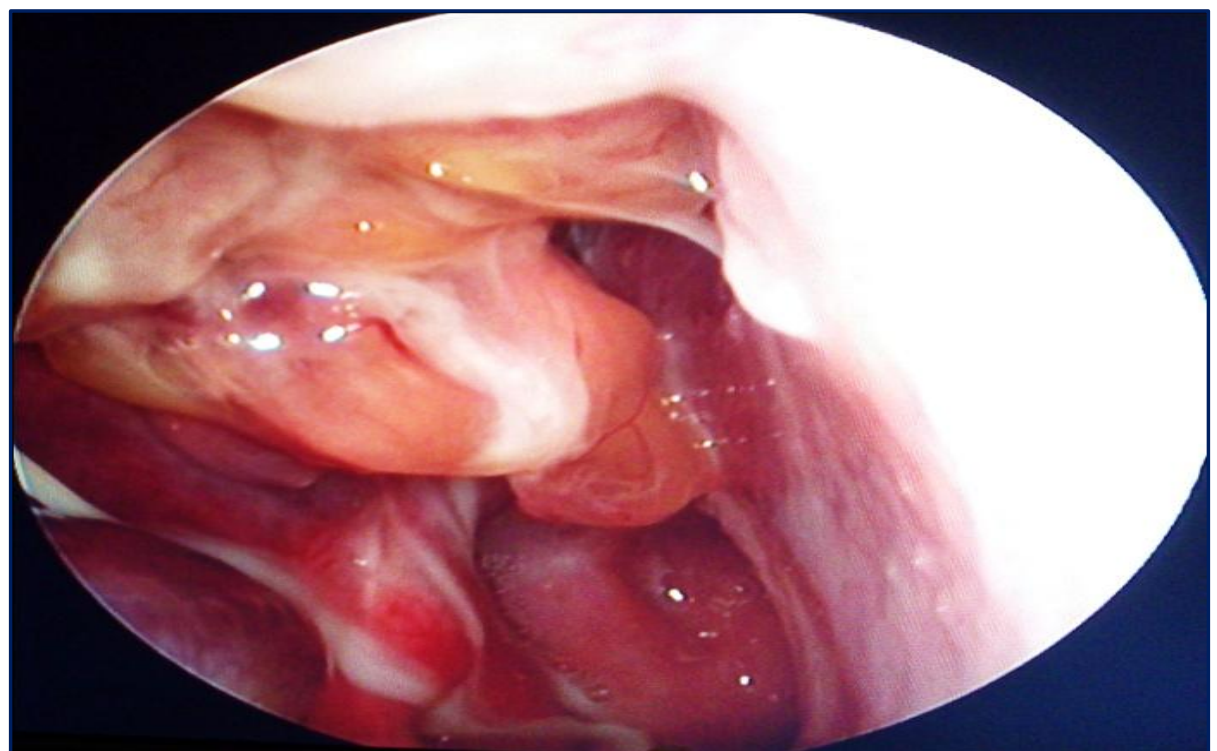

Fig2:: Preopertive nasal endoscopy showing polypoidal mass in Rt. nasal cavity arising from middle meatus

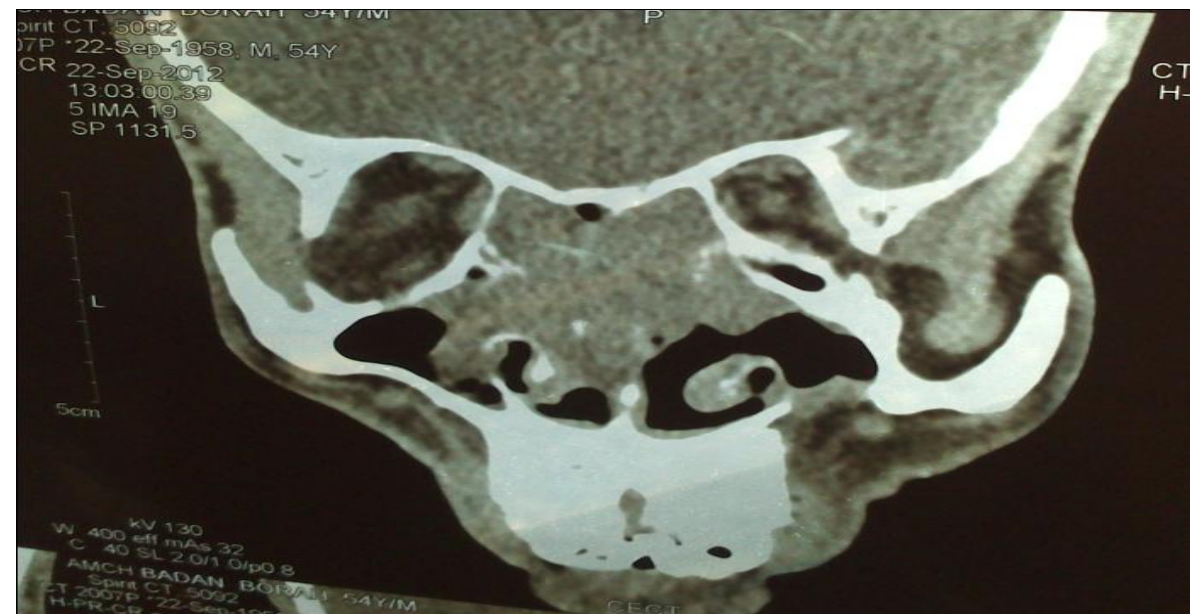

Fig3:CT scan Nose and PNS coronal section showing bilateral involvement of nasal cavity, ethmoidal sinuses , Rt. Maxillary sinus

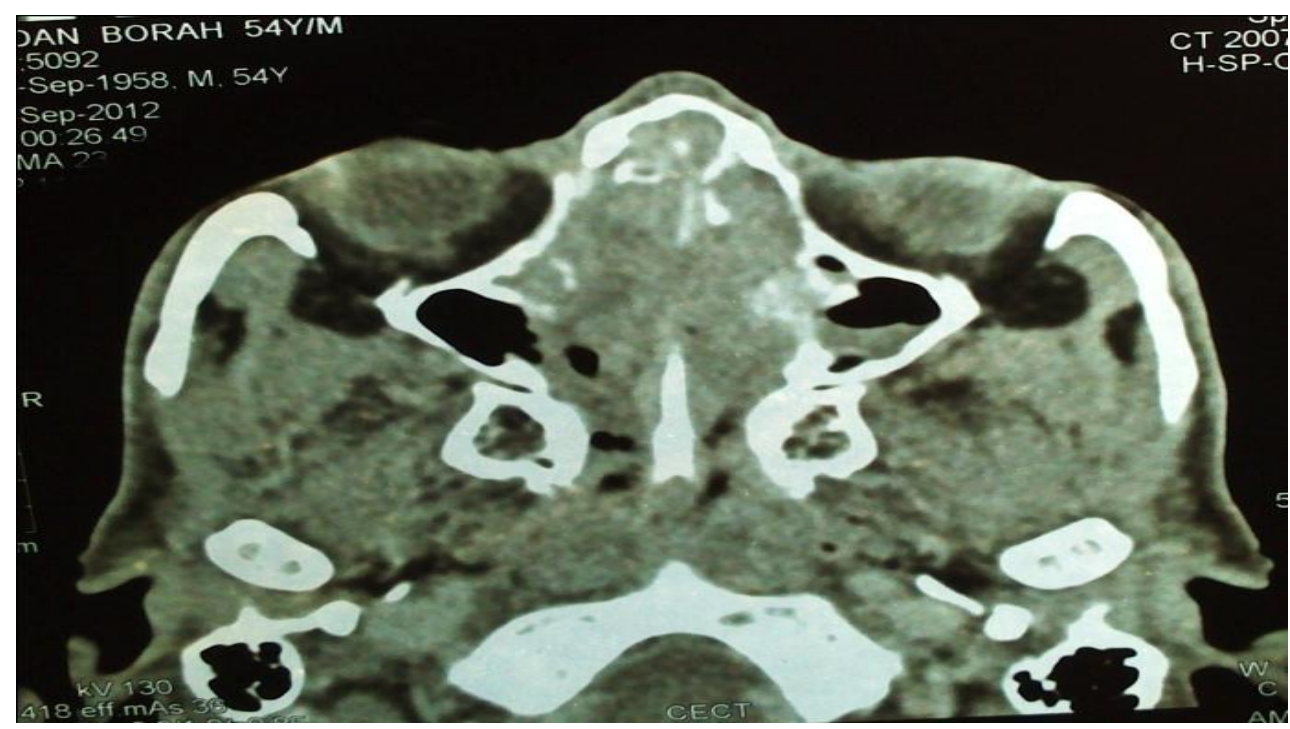

Fig4:CT scan Nose and PNS Axial section showing bilateral involvement of nasal cavity, ethmoidal sinuses , Rt. Maxillary sinus 


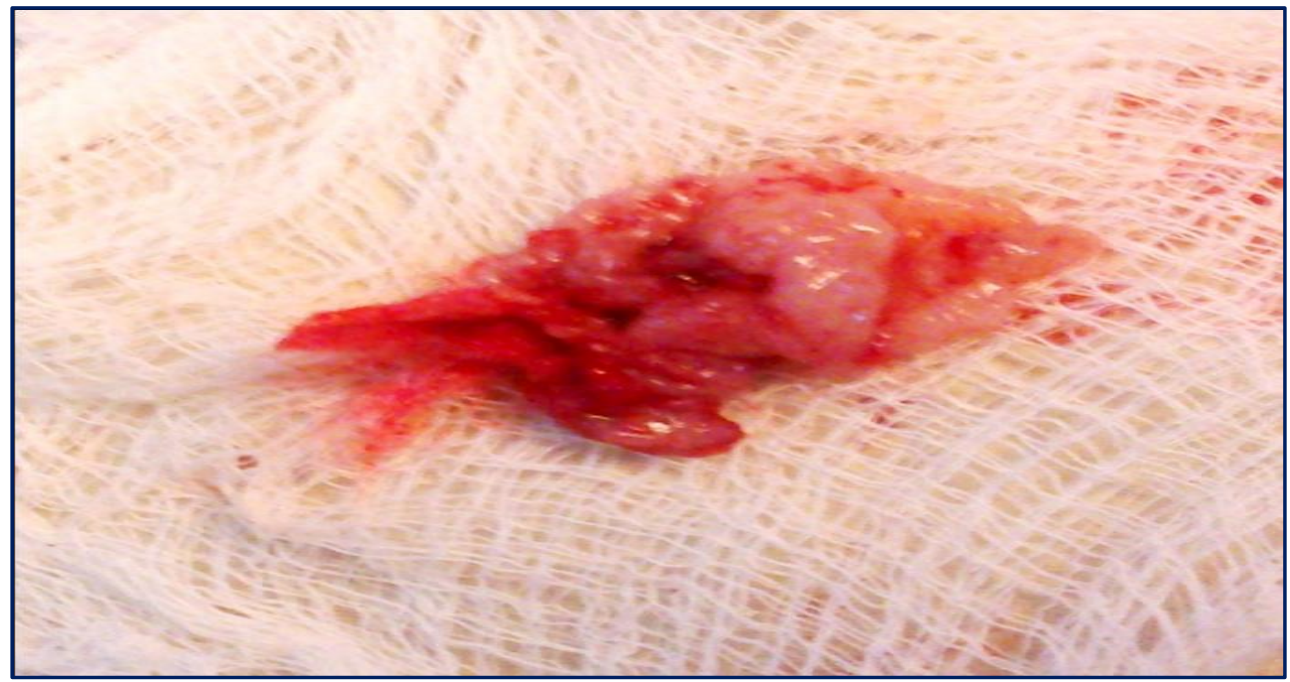

Fig5:Excised mass endoscopically

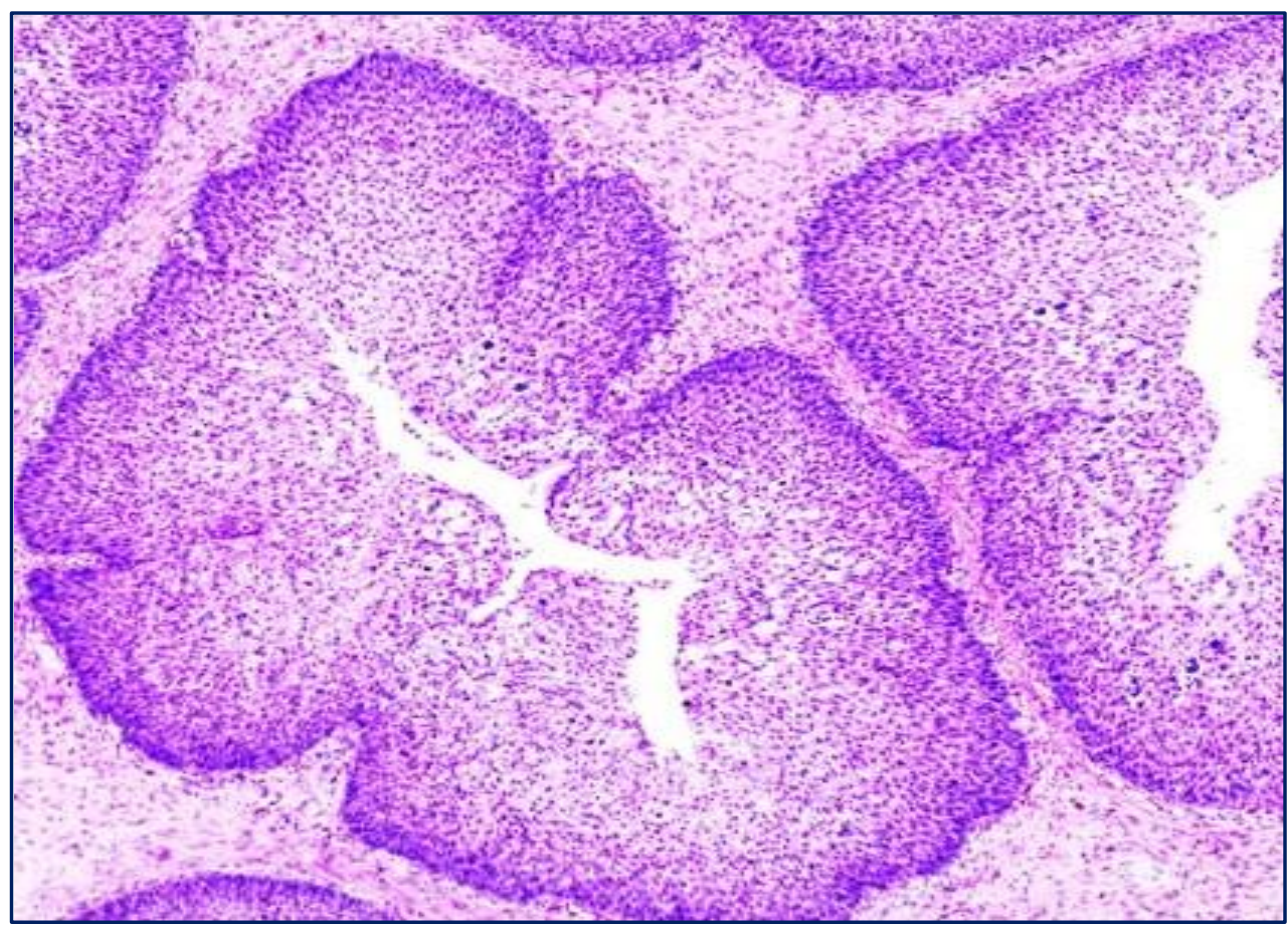

Fig \# 6: HPE Picture of Inverted Papilloma 